\title{
Determination of Predictive Isokinetic Indicators for Return to Sport at 6 Months after ACL Surgery with Semitendinous and Gracilis Tendons
}

\author{
Maude Traulle ${ }^{1,2}$, Marc Linard ${ }^{1}$, Amaury Vandebrouck ${ }^{3}$, Pascal Duffiet ${ }^{3}$, Louis Ratte ${ }^{3}$ and Florian Forelli ${ }^{1,2, *}$ \\ ${ }^{1}$ Researcher Physical Therapist in OrthoLab, Clinic of Domont, France \\ ${ }^{2}$ Co-director OrthoLab, Clinic of Domont, France \\ ${ }^{3}$ Knee Orthopaedic Surgeon, Clinic of Domont, France
}

\section{Abstract}

Background: Numerous evaluation criteria are found in the literature to determine the resumption of sport in patients with anterior cruciate ligament (ACL) surgery. Nevertheless, no consensus can conclude today on precise indicators to determine the return to sport (RTS) at 6 months after ACL surgery.

Aim: The purpose of this study is to determine whether isokinetic evaluation has indicators representative of the functional status of the knee after ACL surgery with semitendinosus and gracilis tendons (STG) to RTS.

Methods: Twenty-two patients, 6.2 months after ACL surgery with STG participated in the study. A correlation was sought between the International Knee Documentation Committee (IKDC) subjective form and the following isokinetic parameters for flexors and extensors at angular velocities of $60 \%$ and $240^{\circ}$ s: Peak Torque (PT), Flexors /Extensors ratio, PT $/ \mathrm{kg}$, and the total work.

Results: The statistical analysis found significant correlations between the IKDC subjective form is PT/ $\mathrm{kg}$, PT and total work with the exception of $60 \%$ flexors. No correlation was found for the flexor $/$ extensor ratio.

Conclusion: PT, PT $/ \mathrm{kg}$, total work of extensors and flexors at $240 \%$ s and extensors at $60 \%$ spear to be the best indicators of knee functional status for sports recovery after ACL surgery

\section{Abbreviation}

ACL: Anterior Cruciate Ligament, ACLR: Anterior Cruciate Ligament Reconstruction, ACL-RSI: Anterior Cruciate Ligament-Return to Sport after Injury, BMI: Body Mass Index, CI: Confidence Index, F/E: Flexors / Extensors, IKDC: International Knee Documentation Committee, KOOS: Knee injury and Osteoarthritis Outcome Score, PT: Peak Torque, RTS: Return To Sport, SD: Standard Deviation, STG: Semitendinous and Gracilis tendons.

\section{Introduction}

The evaluation criteria for the RTS of patients with ACLR remain non-consensual. Despite the use of forms (IKDC, KOOS, Lyshom, etc.) [1-19], it appears that the best indicators in terms of muscular strength, neuromotor abilities and psychosocial level give only a partial indication performance and fail to predict the most optimal risk of recurrence sometimes important $[4,10]$.

Among these forms, the IKDC subjective addresses satisfactory reliability criteria, with a sensitivity of 0.82 , a specificity of 0.88 , a test-retest of 0.9412 and an ICC of 0.92 at 6 months after ACLR. $[6,11,15,18,20-22]$

Combined with the functional forms, isokinetic dynamometer testing is the gold standard for ligamentous knee muscle assessment, thanks to the safety of the examination and the reproducibility of the results $[7,8,23,24]$. If the literature evokes several angular velocities to evaluate different parameters of muscle strength, it seems that the use of slow speed $\left(60^{\circ}, 90^{\circ} / \mathrm{s}\right)$ associated with a small series of contraction ( 4 to 6 repetitions) and fast speed $\left(180^{\circ}, 240^{\circ}, 300^{\circ} / \mathrm{s}\right)$ associated with a large series of contractions (15 to 20 repetitions), are the most appropriate tests in the evaluation after ACL surgery at 6 months, in a concentric mode $[1,25,26]$.

However, there is no consensus on the speeds and parameters studied (PT, PT / kg, Total Work, etc.). Moreover, this evaluation in

\section{Publication History:}

Received: July 09, 2019

Accepted: August 26, 2019

Published: August 28, 2019

Keywords:

ACL, IKDC subjective form, Isokinetic, Return to sport, Correlation open kinetic chain is moving away from the functional aspect of the athlete rather accustomed to alternate the kinetic chain open and closed in his practice as well as contractions concentric and eccentric.

The purpose of this study is to determine whether the isokinetic evaluation has indicators representative of the functional status of the knee after ACLR with STG for RTS.

\section{Materials and Method}

Twenty-two subjects who underwent ACLR with STG for 6 months participated in the study. To integrate the study, the subjects had to meet the following inclusion criteria: be 18 to 50 years old [10,27], understand French, have benefited from ACLR with STG for 6 months (more or at least one month) $[1-5,10,12,22,28,29]$. Women and men are included in this study.

"Corresponding Author: Florian Forelli, Department of Rehabilitation and Functional Exploration, Domont Clinic, 85 route de Domont, 95330 Domont, France; E-mail: fforelli@capio.fr

Citation: Traulle M, Linard M, Vandebrouck A, Duffiet P, Ratte L, et al. (2019) Determination of Predictive Isokinetic Indicators for Return to Sport at 6 Months after ACL Surgery with Semitendinous and Gracilis Tendons. Int J Phys Ther Rehab 5: 153. doi: https://doi.org/10.15344/2455-7498/2019/153

Copyright: (C) 2019 Oertwig et al. This is an open-access article distributed under the terms of the Creative Commons Attribution License, which permits unrestricted use, distribution, and reproduction in any medium, provided the original author and source are credited. 
Citation: Traulle M, Linard M, Vandebrouck A, Duffiet P, Ratte L, et al. (2019) Determination of Predictive Isokinetic Indicators for Return to Sport at 6 Months after ACL Surgery with Semitendinous and Gracilis Tendons. Int J Phys Ther Rehab 5: 153. doi: https://doi.org/10.15344/2455-7498/2019/153

Page 2 of 4

In order to have comparable and analysable results, the following exclusion criteria were implemented: pain in the operated and nonoperated limb, traumatic history of the lower limbs during the last six months [21], concomitant ligament lesions in the rupture of the ACL $[27,29,30]$, operative history of knee [21]. The presence of suture or meniscal resection did not represent an exclusion criterion $[2,8,22,29,31]$.

Before the isokinetic measurements were taken, each participant warmed up on a treadmill for 10 minutes at $5 \mathrm{~km} / \mathrm{h}$ [32].

Two tests were set up, in connection with the literature, to record measurements of the different muscular components. The first test was done at $60^{\circ} / \mathrm{s}[5,8,12,16,22,25,27,28,33,34]$, in concentric, and included 1 series of 4 repetitions on each limb. The second test was performed at $240 \% \mathrm{~s}[5,33,34]$, in concentric, and included 1 series of 20 repetitions on each limb. A rest period of $30 \mathrm{~s}$ was set up between each of the two series. In addition, a series of 6 contractions were performed on each limb for learning purposes in order to have objective and exploitable results during the measurements.

The tests were always done in the same order, first at $60 \% \mathrm{~s}$ then at $240 \%$. All the subjects first performed the evaluation on the unoperated limb and then operated [25,35].

After performing the isokinetic tests, each subject was asked to answer the IKDC subjective form.

\begin{tabular}{|l|l|}
\hline & Experimental Group (average \pm SD) \\
\hline Age $(\mathrm{a})$ & $31,8 \pm 7,01$ \\
\hline Size $(\mathrm{m})$ & $1,74 \pm 0,11$ \\
\hline Weight $(\mathrm{kg})$ & $73,4 \pm 16,8$ \\
\hline BMI $\left(\mathrm{kg} / \mathrm{m}^{2}\right)$ & $23,9 \pm 3,7$ \\
\hline Sex $(\mathrm{M} / \mathrm{F})$ & $15 / 7$ \\
\hline Operated Knee (Right/Left) & $9 / 13$ \\
\hline
\end{tabular}

Table 1: Demographics of the population.

\section{Statistical analysis}

Statistical analyses were performed on the $\mathrm{R}^{\circ}$ software ( $\mathrm{R}$ Development Core Team 2011, Bell Laboratories, Murray Hill, NJ, USA) after collecting and exporting the data to Excel ${ }^{\circ}$.

Shapiro Wilk's test was used to assess whether the variables studied followed a normal distribution. Thus, the present study used the non-parametric Kendall Tau correlation statistical test to analyse the correlation between the IKDC subjective form score and the isokinetic measurements. The confidence level is predefined such that $\mathrm{CI}=95 \%$ and the level of significance is $\alpha=0.05$.

\section{Results}

The overall results are presented in Table 2 .

Statistical analysis revealed significant correlations between IKDC subjective form and all $\mathrm{PT} / \mathrm{kg}$ variables in extension and flexion, in concentric at 60 and $240 \%$ s, all PT variables in concentric at 60 and $240 \%$ s and the total work done at $60 \%$ s in extension and at $240 \% \mathrm{~s}$ in flexion and extension.

\begin{tabular}{|c|c|c|}
\hline Variables & Correlation Coefficient & $\rho$-value \\
\hline PT Ext $/ \mathrm{kg} \_60^{\circ} / \mathrm{s}$ & 0.5339488 & 0.0005649 \\
\hline PT Flex $/ \mathrm{kg} \_60^{\circ} / \mathrm{s}$ & 0.3640491 & 0.01894 \\
\hline PT Ext $/ \mathrm{kg} \_240^{\circ} / \mathrm{s}$ & 0.5450668 & 0.0004529 \\
\hline PT Flex $/ \mathrm{kg} \_240^{\circ} / \mathrm{s}$ & 0.3656423 & 0.01885 \\
\hline F/E_60\% $/$ s Ratio & 0.07002607 & 0.6511 \\
\hline F/E_240\% /s Ratio & -0.008753259 & 0.9549 \\
\hline Total Work Ext con_60\% $/ \mathrm{s}$ & -0.4201564 & 0.006665 \\
\hline Total Work Flex con_6 $6{ }^{\circ} / \mathrm{s}$ & -0.1312989 & 0.3965 \\
\hline Total Work Ext con_ $240^{\circ} / \mathrm{s}$ & -0.472676 & 0.002271 \\
\hline Total Work Flex con_240\% $/ \mathrm{s}$ & -0.437663 & 0.004711 \\
\hline
\end{tabular}

Table 2: Results of the correlations obtained between the different variables and the subjective IKDC.

No correlation was found between the IKDC subjective score and the $\mathrm{F} / \mathrm{E}$ ratio irrespective of the speed studied on the operated leg as well as for the total flexion work at $60 \%$ s.

\section{Discussion}

Recall that the purpose of this study is to determine if the isokinetic evaluation has indicators representative of the functional state of the knee after ACLR for RTS.

The study by Haillotte et al, [9] found similar results in this study, concerning the flexor muscles of the knee. The latter found correlations between the IKDC subjective score and the hamstring PT deficits at a rate of $240 \% \mathrm{~s}(\mathrm{p}<0.01)$, and no correlation was found with the quadriceps at $240 \%$ s. However, various factors were different from the present study: the subjects were ACL operated with fascia lata, patellar tendon and STG graft, their muscle strength measurements were made at isokinetic speed was $90 \%$ s (1 series of 8 repetitions). In view of the difference in protocol, it could be hypothesized that PT of knee extensors should be studied at different isokinetic angular velocities for ACLR.

With regard to the results found at the speed of $60 \%$ of the total work, various hypotheses can be emitted.

The first hypothesis is that total work better reflects the muscular endurance component. As a result, various authors [19,26] have suggested that in order to reflect the endurance component, high isokinetic velocity is required with an important number of repetitions. Thus, we can think that a speed of $60^{\circ} / \mathrm{s}$ with only 5 repetitions is not representative of the muscular endurance component. This is in agreement with the study by Kaminska et al. [34]. The latter found no significant difference in total work between an ACLR population (postoperative recruitment range of 4 to 12 months) and a healthy population at the angular rate of $60 \%$ s. However, as in the present study, significant differences were found at the angular velocity of $240 \%$ s. Kaminska et al. [34] therefore submitted the idea that a fast speed was needed to more accurately assess the total work deficits for ACLR, which is in line with the results of this study.

The second hypothesis is that subjective functional scores are more closely related to the functional level of the extensor apparatus as suggested by Logersted et al, [1,7]. Thus the IKDC subjective score would be more sensitive to assess the functional level of knee extensors than flexors. 
Citation: Traulle M, Linard M, Vandebrouck A, Duffiet P, Ratte L, et al. (2019) Determination of Predictive Isokinetic Indicators for Return to Sport at 6 Months after ACL Surgery with Semitendinous and Gracilis Tendons. Int J Phys Ther Rehab 5: 153. doi: https://doi.org/10.15344/2455-7498/2019/153

Page 3 of 4

In the present study no correlation was found between the IKDC subjective score and the F/E ratios of the operated limb. Our results are consistent with those of Lentz et al. [36]. The latter were interested in patients who had not yet resumed their sport at the same level as before the injury at 6 months. These results were even less correlated if, in addition to not having resumed activity, the patient was afraid to resume his activity.

No correlation was also found for differences in F/E ratio between operated and non-operated legs. As the ratios themselves had shown no correlation with the IKDC subjective score, it would have been unlikely that their difference would be.

With respect to the $\mathrm{PT} / \mathrm{kg}$, our results found significant correlations with the IKDC subjective score $[1,31,37]$. Lentz and al [36] evaluated the correlations between the PT kg of the quadriceps and the angular velocity of $60 \%$ at 6 months after ACLR and found significant correlations with all the groups studied. Kong et al., [22], investigated the correlation between PT/ $\mathrm{kg}$ differences, at $60 \% \mathrm{~s}$ angular velocity in concentric mode, and three different jump tests. Their study shows significant correlations between the results obtained in the 3 tests and the $\mathrm{PT} / \mathrm{kg}$ of extensors and flexors.

\section{Limitations}

The present study was performed on a small sample and on a single population operated with STG, so it is not generalizable to all patients who have undergone ACL surgery. It would have been interesting to compare, in a future study, the functional indicators between the different grafts used and to determine their functional impact.

Similarly, the evaluation of the LCA on the criteria of strength, neuromotive and psychosocial agility, it would have been relevant to correlate our results at different hop tests or at the ACL-RSI scale.

Finally, the study of different speeds described in the literature would have made it possible to determine the choice of the optimal speed in the evaluation of the return to sport most representative of the function of the knee after ACL surgery.

\section{Conclusion}

Our results compared to those found in the literature show that the PT, PT $/ \mathrm{kg}$, the total work of extensors and flexors at $240^{\circ} / \mathrm{s}$ and extensors at $240 \%$ s seem to be the best indicators of the functional status of the knee, view of the return to sport after ACL surgery. On the other hand, the ratio $\mathrm{F} / \mathrm{E}$ and the total work of the flexors at $60 \%$ do not seem to provide specific indications for sports recovery. Although there are no consensus indicators to date, this study and the literature seem to agree on the joint use of force, neuromotive and psychosocial agility parameters to determine sport recovery appropriately for the patients undergoing ACLR.

\section{Competing Interests}

The authors declare that they have no competing interests.

\section{References}

1. Logerstedt D, Lynch A, Axe MJ, Snyder-Mackler L (2013) Pre-operative quadriceps strength predicts IKDC2000 scores 6months after anterior cruciate ligament reconstruction. The Knee 20: 208-212.
2. Harput G, Ozer H, Baltaci G, Richards J (2018) Self-reported outcomes are associated with knee strength and functional symmetry in individuals who have undergone anterior cruciate ligament reconstruction with hamstring tendon autograft. The Knee 25: 757-764.

3. Pua YH, Bryant AL, Steele JR, Newton RU, Wrigley TV, et al. (2008) Isokinetic Dynamometry in Anterior Cruciate Ligament Injury and Reconstruction. Ann Acad Med Singapore 37: 330-340.

4. Kvist J (2004) Rehabilitation Following Anterior Cruciate Ligament Injury: Current Recommendations for Sports Participation. Sports Medicine 34 : 269-280.

5. Hohmann E, Tetsworth K, Glatt V (2019) The hamstring/quadriceps ratio is an indicator of function in ACL-deficient, but not in ACL-reconstructed knees. Arch Orthop Trauma Surg 139: 91-98.

6. Ra HJ, Kim HS, Choi JY, Ha JK, Kim JY, et al. (2014) Comparison of the ceiling effect in the Lysholm score and the IKDC subjective score for assessing functional outcome after ACL reconstruction. The Knee 21: 906-910.

7. Logerstedt D, Di Stasi S, Grindem H, Lynch A, Eitzen I, et al. (2014) SelfReported Knee Function Can Identify Athletes Who Fail Return-to-Activity Criteria up to 1 Year After Anterior Cruciate Ligament Reconstruction: A Delaware-Oslo ACL Cohort Study. J Orthop Sports Phys Ther 44: 914-923.

8. Larsen JB, Farup J, Lind M, Dalgas U (2015) Muscle strength and functional performance is markedly impaired at the recommended time point for sport return after anterior cruciate ligament reconstruction in recreational athletes. Hum Mov Sci 39: 73-87.

9. Haillotte G, Hardy A, Granger B, Noailles T, Khiami F, et al. (2017) Early strength recovery after anterior cruciate ligament reconstruction using the fascia lata. Orthop Traumatol Surg Res 103: 1021-1025.

10. Ardern CL, Webster KE, Taylor NF, Feller JA (2011) Return to sport following anterior cruciate ligament reconstruction surgery: a systematic review and meta-analysis of the state of play. Br J Sports Med 45: 596-606.

11. Irrgang JJ, Anderson AF, Boland AL, Harner CD, Kurosaka M, et al. (2001) Development and Validation of the International Knee Documentation Committee Subjective Knee Form. Am J Sports Med 29: 600-613.

12. Teitsma XM, van der Hoeven $H$, Tamminga $R$, de Bie RA (2014) Impact of Patient Sex on Clinical Outcomes: Data From an Anterior Cruciate Ligament Reconstruction Registry, 2008-2013. Orthop J Sports Med 2: 232596711455063.

13. Reinke EK, Spindler KP, Lorring D, Jones MH, Schmitz L, et al. (2011) Hop tests correlate with IKDC and KOOS at minimum of 2 years after primary ACL reconstruction. Knee Surg Sports Traumatol Arthrosc 19: 1806-1816.

14. Irrgang JJ, Anderson AF, Boland AL, Harner CD, Neyret $P$, et al. (2006) Responsiveness of the International Knee Documentation Committee Subjective Knee Form. Am J Sports Med 34: 1567-1573.

15. Higgins LD, Taylor MK, Park D, Ghodadra N, Marchant M, et al. (2007) Reliability and validity of the International Knee Documentation Committee (IKDC) Subjective Knee Form. Joint Bone Spine 74: 594-599.

16. Czaplicki A Jarocka M, Walawski J (2015) Isokinetic Identification of Knee Joint Torques before and after Anterior Cruciate Ligament Reconstruction. PLOS ONE 10: e0144283.

17. Petersen $W$, Taheri P, Forkel P, Zantop T (2014) Return to play following ACL reconstruction: a systematic review about strength deficits. Arch Orthop Trauma Surg 134: 1417-1428.

18. Hambly K, Griva K (2010) IKDC or KOOS: Which One Captures Symptoms and Disabilities Most Important to Patients Who Have Undergone Initial Anterior Cruciate Ligament Reconstruction? Am J Sports Med 38: 13951404.

19. Norte GE, Hertel J, Saliba SA, Diduch DR, Hart JM, et al. (2018) Quadriceps Neuromuscular Function in Patients With Anterior Cruciate Ligament Reconstruction With or Without Knee Osteoarthritis: A Cross-Sectional Study. J J Athl Train 53: 475-485

20. Zouita Ben Moussa A, Zouita S, Dziri C, Ben Salah FZ (2009) Single-leg assessment of postural stability and knee functional outcome two years after anterior cruciate ligament reconstruction. Ann Phys Rehabil Med 52 : 475-484.

21. Schmitt LC, Paterno MV, Hewett TE (2012) The Impact of Quadriceps Femoris Strength Asymmetry on Functional Performance at Return to Sport Following Anterior Cruciate Ligament Reconstruction. J Orthop Sports Phys Ther 42: 750-759.

22. Kong DH, Yang SJ, Ha JK, Jang SH, Seo JG, et al. (2012) Validation of Functional Performance Tests after Anterior Cruciate Ligament Reconstruction. Knee Surg Relat Res 24: 40-45. 
Citation: Traulle M, Linard M, Vandebrouck A, Duffiet P, Ratte L, et al. (2019) Determination of Predictive Isokinetic Indicators for Return to Sport at 6 Months after ACL Surgery with Semitendinous and Gracilis Tendons. Int J Phys Ther Rehab 5: 153. doi: https://doi.org/10.15344/2455-7498/2019/153

Page 4 of 4

23. Ko MS, Yang SJ, Ha JK, Choi JY, Kim JG, et al. (2012) Correlation between Hamstring Flexor Power Restoration and Functional Performance Test: 2-Year Follow-Up after ACL Reconstruction Using Hamstring Autograft. Knee Surg Relat Res 24: 113-119.

23. Cvjetkovic D, Bijeljac S, Palija S, Talic G, Radulovic T, et al. (2015) Isokinetic Testing in Evaluation Rehabilitation Outcome After ACL Reconstruction. Med Arh 69: 21-23.

23. Pua YH, Ho JY, Chan SAS, Khoo SJ, Chong HC, et al. (2017) Associations of isokinetic and isotonic knee strength with knee function and activity level after anterior cruciate ligament reconstruction: a prospective cohort study. Knee 24: 1067-1074.

23. Cavalcante MLC, Teixeira PRL, Sousa TCS, Lima PO de P, Oliveira RR, et al (2016) Index of fatigue quadriceps in soccer athletes after anterior cruciate ligament reconstruction. Rev Bras Ortop 51: 535-540.

23. Elmlinger BS, Nyland JA, Tillett ED (2006) Knee Flexor Function 2 Years After Anterior Cruciate Ligament Reconstruction With Semitendinosus-Gracilis Autografts. Arthroscopy 22: 650-665.

23. Millet-Barbé B, Rabarin F, Niéto H (2014) Techniques chirurgicales de ligamentoplasties du ligament croisé antérieur. Revue de Chirurgie Orthopédique et Traumatologique 100: 112-116.

23. Lee DY, Karim SA, Chang HC (2008) Return to Sports After Anterior Cruciate Ligament Reconstruction - A Review of Patients with Minimum 5-year Follow-up. Ann Acad Med Singapore 37: 6.

23. Malliopoulos X, Courtot H, Caudin J, Facquez T, Bouilland S, et al. (2013) Test isocinétique précoce après ligamentoplastie antérieure de genou: résultats et conclusions. Journal de Traumatologie du Sport 30: 216-219.

23. Sueyoshi T, Nakahata A, Emoto G, Yuasa T (2017) Single-Leg Hop Test Performance and Isokinetic Knee Strength After Anterior Cruciate Ligament Reconstruction in Athletes. Orthop J Sports Med 5: 232596711773981.

23. Baltaci G, Harput G, Haksever B, Ulusoy B, Ozer H, et al. (2013) Comparison between Nintendo Wii Fit and conventional rehabilitation on functiona performance outcomes after hamstring anterior cruciate ligament reconstruction: prospective, randomized, controlled, double-blind clinical trial. Knee Surg Sports Traumatol Arthrosc 21: 880-887.

23. Dellagrana RA, Diefenthaeler F, Carpes FP, Hernandez SG, de Campos W, et al. (2015) Evidence for isokinetic knee torque asymmetries in male long distance-trained runners. Int J Sports Phys Ther 10: 514-519.

23. Kaminska E, Piontek T, Wiernicka M, Cywinska-Wasilewska G, Lewandowsk J, et al. (2015) Differences in Isokinetic Strength of the Knee Extensors and Flexors in Men with Isolated and Combined Cruciate-Ligament Knee Injury. Journal of Sport Rehabilitation 24: 268-277.

23. Müller U, Krüger-Franke M, Schmidt M, Rosemeyer B (2015) Predictive parameters for return to pre-injury level of sport 6 months following anterior cruciate ligament reconstruction surgery. Knee Surg Sports Traumatol Arthrosc 23: 3623-3631.

23. Lentz TA, Zeppieri G, George SZ, Tillman SM, Moser MW, et al. (2015) Comparison of Physical Impairment, Functional, and Psychosocial Measures Based on Fear of Reinjury/Lack of Confidence and Return-to-Sport Status After ACL Reconstruction. Am J Sports Med 43: 345-353.

23. Zvijac JE, Toriscelli TA, Merrick WS, Papp DF, Kiebzak GM, et al. (2014) Isokinetic Concentric Quadriceps and Hamstring Normative Data for Elite Collegiate American Football Players Participating in the NFL Scouting Combine. J Strength Cond Res 28: 875-883. 